\title{
Técnicas de Cenários e o Método Delphi: visões de futuro para o prédio que abrigou a Fábrica Santa Amélia
}

\section{Scenario Techniques and the Delphi Method: visions of the future for the building that housed the Santa Amélia Factory}

Enviado em: 30/09/2020

Aceito em: 05/01/2021

\author{
Conceição de Maria Belfort de Carvalho ${ }^{1 *}$ \\ Kláutenys Dellene Guedes Cutrim ${ }^{2^{* *}}$ \\ Brenda Rodrigues Coelho Leite $3^{3^{* * *}}$
}

\section{Resumo}

Este artigo apresenta uma proposta de análise de cenários futuros para o prédio onde funcionou a fábrica Santa Amélia, e hoje abriga os cursos de Turismo e Hotelaria da Universidade Federal do Maranhão. O estudo adota como proposta metodológica o método de Delphi, visando à construção de três futuros possíveis para o prédio, para as décadas que correspondem a 2017-2027, a partir do consenso de opiniões dos especialistas/painelistas (sujeitos da pesquisa). Os dados apontam como cenário otimista "O Complexo da fábrica Santa Amélia como destaque de ensino e visitação"; o cenário pessimista "O prédio da fábrica Santa Amélia restaurada para degradação".

Palavras-chave: Técnicas de cenário; Método Delphi; Visões de futuro.

\begin{abstract}
This article presents a proposal for the analysis of future scenarios for the building where the Santa Amélia factory operated, and now houses the Tourism and Hospitality courses of the Federal University of Maranhão. The study adopts as a methodological proposal the Delphi method, aiming at the construction of three possible futures for the building, for the decades corresponding to 2017-2027, based on the consensus of opinions of the experts / panelists (research subjects). The data point as an optimistic scenario "The Complex of the Santa Amélia factory as a highlight of teaching and visitation"; the pessimistic scenario "The Santa Amélia factory building restored to degradation". The study is based on authors such as: Marcial (2005), Cardoso (2005), Cesquim (2009), Kotler (1996).
\end{abstract}

Keywords: scenery techniques; Delphi method; visions of the future.

1 - Professora do Departamento de Turismo e Hotelaria da Universidade Federal do Maranhão e Professora permanente do Programa de Pós-Graduação em Cultura e Sociedade (PGCULT/UFMA).

2 - Professora do Departamento de Turismo e Hotelaria da UFMA e Professora permanente do Programa de Pós-Graduação em Cultura e Sociedade (PGCULT/UFMA).

3 - Mestre do Programa de Pós-Graduação em Cultura e Sociedade (PGCULT/UFMA)

Revista Memória em Rede, Pelotas, v.13, n.24, Jan/Jul.2021 - ISSN- 2177-4129

periodicos.ufpel.edu.br/ojs2/index.php/Memoria 


\section{Introdução}

O Centro Histórico de São Luís, capital maranhense, deu à cidade o título de Patrimônio Cultural da Humanidade e tornou-se seu principal atrativo turístico. Como parte desse cenário, encontra-se o prédio que sediou a fábrica Santa Amélia, ${ }^{4}$ elemento importante do período industrial maranhense, em fins do século XIX, de singular arquitetura portuguesa, e que agora abriga os cursos de Turismo e Hotelaria da Universidade Federal do Maranhão.

O prédio da antiga fábrica viveu um período de degradação e, após sua restauração e requalificação, ainda gera expectativas quanto ao seu futuro, principalmente por parte dos estudantes e da comunidade local. Tendo em vista a expectativa a longo prazo, busca-se, por meio do método de Delphi, a construção de múltiplos cenários futuros para o prédio, para o ano de 2027, por meio de consultas a especialistas que possuem notório conhecimento do lugar e da região onde se localiza. Investiga-se o patrimônio edificado da antiga fábrica não apenas como espaço de ensino, como é proposto em seu projeto de reforma, mas também como um possível atrativo turístico, por sua viabilidade.

Para a elaboração dos cenários, realizou-se o levantamento dos fatores de futuro e suas interrelações, que são capazes de direcionar a construção do que está por vir. Como resultado, três cenários alternativos foram construídos, sendo o primeiro em um contexto de futuro possível, o segundo em um cenário otimista em relação ao possível, e o terceiro em um cenário pessimista. Os cenários também mostraram as fragilidades e futuras dificuldades pelas quais o prédio poderá passar ao desenvolver suas atividades conforme vão se apresentando os fatores de futuro.

No espaço deste artigo, inicialmente faz-se um percurso histórico sobre o que significou a revolução industrial para o Maranhão pontuando o breve período fabril no Estado. Em seguida, apresentam-se as perspectivas de um futuro possível para o prédio da antiga fábrica Santa Amélia.

\section{Breve história da industrialização no Maranhão}

No Maranhão, a industrialização é marcada pela queda da economia de base agroexportadora. A decadência das lavouras de açúcar e algodão e a promulgação da

4 - O prédio onde foi instalada a fábrica Santa Amélia inaugurou em 1902 no local onde inicialmente funcionou a fábrica da Companhia de Lanifícios Maranhense cuja inauguração se deu em 1892. A principal atividade da fábrica Santa Amélia baseava-se no beneficiamento de algodão. Seu encerramento total aconteceu no ano de 1966. 
Lei Áurea vão possibilitar que se estabeleça no Estado um parque fabril, a partir da reunião de capitais da aristocracia rural e da burguesia comercial, que vêem na indústria têxtil uma saída para a circulação do capital.Em 1895, o Maranhão possuía dezessete fábricas; dentre elas destacamos catorze indústrias têxteis, que trabalhavam com fiação e tecidos de algodão, de cânhamo, de lã, e fiação de meias. (CARVALHO, 2009).

A industrialização possibilitou aos moradores da capital São Luís experimentarem o progresso e as tecnologias dele resultantes, tais como o telefone (1880), as máquinas de costura, a iluminação elétrica (1895), o telégrafo (1895), automóveis, bondes. Tem destaque uma arquitetura funcional como a das fábricas e, por extensão, de vilas operárias, que foram se formando na cidade. (LOPES, 2004).

O parque fabril maranhense, nos últimos vinte anos do século XIX, cresceu elevando o Maranhão a segundo Estado brasileiro mais industrializado, perdendo apenas para Minas Gerais. (CARVALHO, 2009)

A partir da instalação das fábricas, no entorno do centro comercial de São Luís, a cidade vê nascer os primeiros bairros proletários, nos arredores desses núcleos industriais. Nas proximidades da Companhia de Fiação e Tecidos Rio Anil surgiu o bairro do Anil; em torno da Companhia Fabril Maranhense surgiu o bairro Fabril; nos arredores da Companhia de Fiação e Tecidos Cânhamo nasceu o bairro Madre Deus. O surgimento desses bairros garantia uma melhor economia de tempo e deslocamento dos operários e,também, a força de trabalho por longas horas, assim como iria assegurar maior assiduidade na produção, demarcando ainda o espaço do operário: as vilas operárias.

Apesar de parecer promissora, a industrialização não prosperou. As fábricas maranhenses não criaram, como as do sul do país, uma dinâmica em seu parque industrial. Questões como as elevadas tarifas alfandegárias, fretes exorbitantes, inúmeros feriados, dificuldades de comunicação, falta de estradas, carência de crédito nos bancos contribuíram para que esse sonho não lograsse êxito. A produção industrial importava máquinas dos países centrais investindo, assim, um grande capital. Esses são apenas alguns dos fatores responsáveis pela falência do projeto fabril.

Tem destaque o caso da fábrica Santa Amélia, que viveu bons tempos de produção nas décadas de 40 e 50 , mas que viu sua prosperidade minguar com a concorrência das indústrias da região sul do Brasil, equipadas com novos e modernos 
maquinários movidos à energia, enquanto a fábrica Santa Amélia ainda se utilizava de teares a vapor e diesel provenientes da tecnologia da Inglaterra do século XIX.

Passado o período de "miragem da industrialização" (MEIRELES, 2008), o Maranhão, particularmente a capital, viu suas fábricas se esvaziarem e os prédios entrarem em estado de abandono, como é o caso da fábrica Santa Amélia.

Construída no final do século XIX, a fábrica Santa Amélia e mais outros imóveis que the serviam de apoio foram desapropriados pelo Decreto Federal n 94.191 de 06 de abril de 1987 e tombada pelo Instituto do Patrimônio Histórico e Artístico Nacional IPHAN. A fábrica foi inscrita na zona de proteção histórica pelo município, por ser consideradaum "exemplar significativo da arquitetura industrial do Maranhão", conforme parecer do conselheiro Roberto Cavalcanti de Albuquerque (Processo de Tombamento n ${ }^{01144-T-85, ~ p . ~ 64) . ~}$

Nessa mesma década, ela foi desapropriada pelo Governo Federal e entregue à Universidade Federal do Maranhão para a instalação do Centro de Artes e da Faculdade de Direito, conforme preconizado em seu Plano Diretor Físico. Os planos da UFMA para esse período não se concretizaram e o patrimônio entrou em estado de degradação.Uma nova tentativa de recuperação e requalificação dessas edificações foi iniciada efetivamente em 2010, com uma nova proposta de torná-la sede dos cursos de Turismo e Hotelaria.Esse novo projeto contou com o apoio financeiro e a participação do Governo Federal, do IPHAN, do Ministério do Turismo e do Ministério da Educação.

Tais tentativas foram importantes, afinal são benéficos "todos os esforços e procedimentos necessários para garantir a um monumento histórico, o tanto quanto possível, a sua perenidade e transmissão para o futuro" (KUHL, 2006 apud LIMA, 2006, p. 206). Nesse sentido, o resgate do prédio da fábrica Santa Amélia, por meio do projeto de mudança do patrimônio industrial em espaço de ensino, se apresenta como uma possibilidade de recuperação e revitalização.

\section{Da recuperação à revitalização: visões de futuro para o prédio que abrigou a fábrica Santa Amélia}

A antiga fábrica teve o seu espaço adaptado com a criação de um Hotel Escola, salas de aulas, laboratórios, auditórios, banheiros. Destaca-se,no Processo de n ${ }^{\circ}$ 198536, apresentado pelo IPHAN, a idealização de um espaço museográfico. A Sala da Memória da fábrica Santa Amélia, contará a história da indústria têxtil no Brasil e no Maranhão, apresentará fotos temáticas sobre a paisagem urbana de São Luís e 
sobre a Industrialização, sobre as fábricas de Cândido Ribeiro e sobre a fábrica de Tecido Santa Amélia, incluindo-se imagens do seu processo de restauro. O resultado do projeto incorpora ao reuso da fábrica a manutenção de suas características originais (a essência fabril) tanto quanto a modernização do espaço.

Após as restaurações e as adaptações feitas no espaço com investimentos do Ministério da Educação e do Turismo no projeto de reforma, criou-se uma expectativa quanto ao seu novo uso e função pelos cursos de Turismo e Hotelaria e também como parte ativa e pulsante da cidade com o surgimento de uma nova sinergia urbanística, paisagística e turística para o Centro de São Luís.

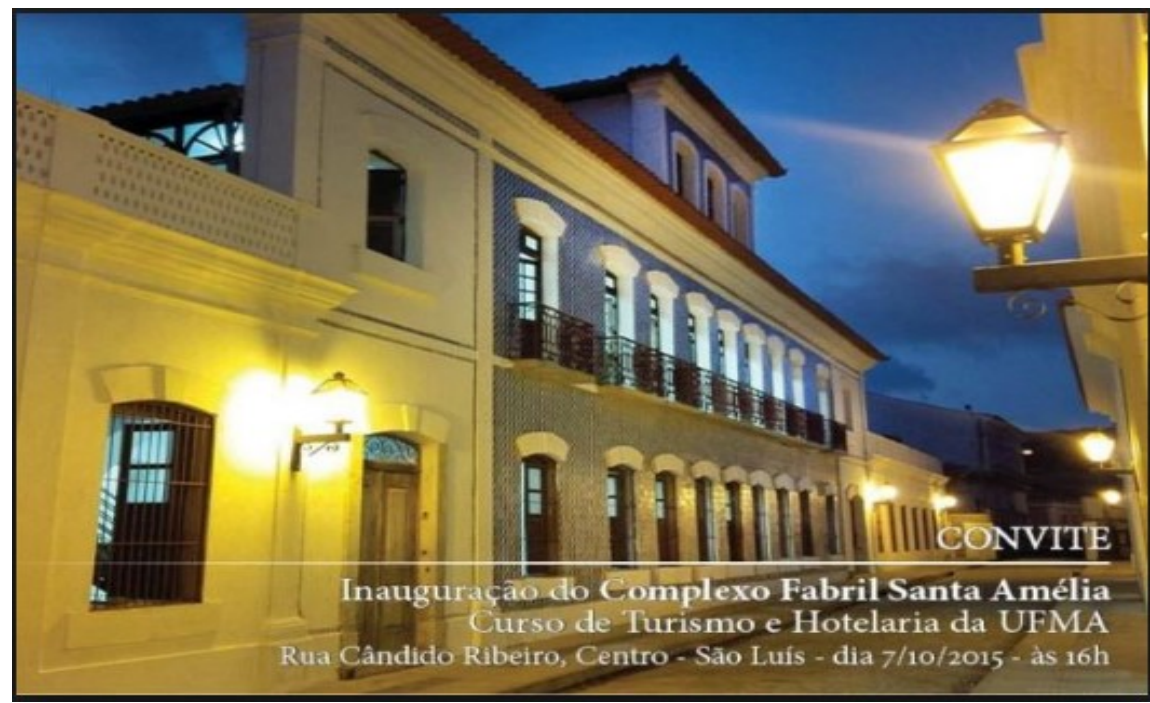

Figura 1: Convite de inauguração do prédio onde funcionarão os cursos de Turismo e Hotelaria Fonte: Site da UFMA (www.ufma.com.br)

Diante dessas mudanças, surge uma pergunta que orienta este trabalho sobre o futuro do prédio da antiga fábrica Santa Amélia: quais seriam as possíveis novas relações sociais, culturais, turísticas e econômicas pós-revitalização da fábrica? Com o propósito de responder a essa pergunta, o objetivo geral aqui traçado foi o de construir três futuros possíveis para o prédio nas décadas que correspondem a 2017 - 2027, a partir do consenso de opiniões dos especialistas/painelistas (sujeitos da pesquisa).

Para a construção dos cenários possíveis optou-se pela divisão dos futuros possíveis: um otimista em relação ao possível e um pessimista. Todos os múltiplos cenários que serão construídos possuem possibilidades de acontecer, pois o futuro é construído no presente, e são as decisões do presente, tomadas ao longo do caminho, que determinarão qual cenário será o vivenciado. Vale ressaltar que por especialistas entende-se não somente os sujeitos que possuem qualificação acadêmica ou de 
reconhecido trabalho na área, como também sujeitos de notório saber, como aqueles que vivenciaram ou que vivenciam o objeto de pesquisa. Participaram da pesquisa onze especialistas.

A escolha dos painelistas foi realizada previamente (escolha não probabilística), com base no conhecimento dos sujeitos sobre o prédio da antiga fábrica Santa Amélia e/ou região e passou também pelos seguintes critérios: cargo ocupado, relação com o objeto, como disposto na tabela a seguir:

Tabela 1: Categoria dos Especialistas Fonte: Autoria própria

\begin{tabular}{|c|c|c|}
\hline ESPECIALISTA & CARGO & RELAÇÃO COM O OBJETO \\
\hline \multicolumn{3}{|c|}{ Grupo 1 - Área acadêmica } \\
\hline 1 & Professor (a) & $\begin{array}{c}\text { Desenvolve trabalhos na área de } \\
\text { museus e patrimônio }\end{array}$ \\
\hline 2 & Professor (a) & $\begin{array}{l}\text { Desenvolve trabalhos na área de } \\
\text { planejamento, gestão e marketing }\end{array}$ \\
\hline 3 & Discente & $\begin{array}{l}\text { Discente do curso de turismo com } \\
\text { prática em pesquisa e extensão }\end{array}$ \\
\hline 4 & Professor (a) & $\begin{array}{c}\text { Representante Institucional da } \\
\text { UFMA }\end{array}$ \\
\hline \multicolumn{3}{|c|}{ Grupo 2 - Agentes locais e públicos. } \\
\hline 5 & Delegatário de Serventia Extra Judicial & $\begin{array}{c}\text { Participante do processo de licitação } \\
\text { de obras do prédio daantiga fábrica } \\
\text { Santa Amélia }\end{array}$ \\
\hline 6 & Delegado de Policia & $\begin{array}{c}\text { Vinculo familiar e patrimonial com a } \\
\text { fábrica Santa Amélia }\end{array}$ \\
\hline 7 & Comunidade & $\begin{array}{l}\text { Morador adjacente ao prédio da } \\
\text { antiga fábrica Santa Amélia }\end{array}$ \\
\hline 8 & $\begin{array}{c}\text { Representante Institucional da Secretária } \\
\text { Municipal de Turismo }\end{array}$ & $\begin{array}{l}\text { Responsabilidade em fomentar } \\
\text { políticas públicas de preservação, } \\
\text { promoção, entre outras esferas, da } \\
\text { cidade de São Luís. }\end{array}$ \\
\hline \multicolumn{3}{|c|}{ Grupo 3 - Agentes e Instituições ligadas ao Patrimônio } \\
\hline 9 & Técnico Iphan & $\begin{array}{c}\text { Fiscalização e preservação da área } \\
\text { e patrimônios tombados }\end{array}$ \\
\hline 10 & Arquiteto & \begin{tabular}{|} 
Responsável pela execução do \\
projeto de restauração e \\
requalificação do prédio da fábrica \\
Santa Amélia \\
\end{tabular} \\
\hline 11 & Guia de turismo & \begin{tabular}{|c|}
$\begin{array}{c}\text { Notório saber sobre a região onde } \\
\text { se localiza o prédio da antiga fábrica } \\
\text { Santa Amélia }\end{array}$ \\
\end{tabular} \\
\hline
\end{tabular}

O desejo de prever o futuro é algo constante na história da humanidade, a fim de minimizar riscos de decisões do presente. A tentativa de prever o "porvir" prepara e 
motiva a sociedade a planejar suas ações, seja no dia-a-dia, planejando a rotina da casa, seja realizando um planejamento turístico para promover uma cidade ou num planejamento de mercado que possa direcionar uma empresa a se tornar mais eficiente e produtiva.

Conforme destacam Marcial e Grumbach (2005), os estudos previsionais foram modernizados após a Guerra Fria, principalmente no setor militar, pela necessidade de realizar ações estratégicas a fim de posicionar-se sempre à frente do inimigo, e passaram a ser chamados de Estudos Prospectivos.

De acordo com Cesquim (2009), a utilização da palavra prospectiva deve-se ao filósofo, economista e pedagogo francês Gaston Berger em sua obra "A atitude prospectiva", de 1957. O relançamento da expressão por Berger tinha o intuito de diferenciar o termo previsão de prospecção, pois a primeira possuía o significado de construção de um futuro à imagem do passado, além de estar associada às questões proféticas do determinismo de um único futuro. Já a palavra prospecção transmitia a visão de um futuro que é decididamente diferente do passado. Dessa forma, os estudos prospectivos demonstram que o futuro não é cópia do passado, que diferentes ações podem repercutir em diferentes futuros, pois este vai além de prospectar um fato que irá ocorrer, sendo também responsável por demonstrar quais causas e ações do presente irão interferir nas ocorrências futuras. (MARCIAL, 1999, p. 12).

Cardoso et al. (2005) apresentam uma diferenciação da visão prospectiva da previsão tradicional: uma realiza análise do passado e do presente para construção de futuros múltiplos e incertos, enquanto a outra realiza projeção do passado para a construção de um único futuro, conforme demonstra o gráfico da Figura 2:

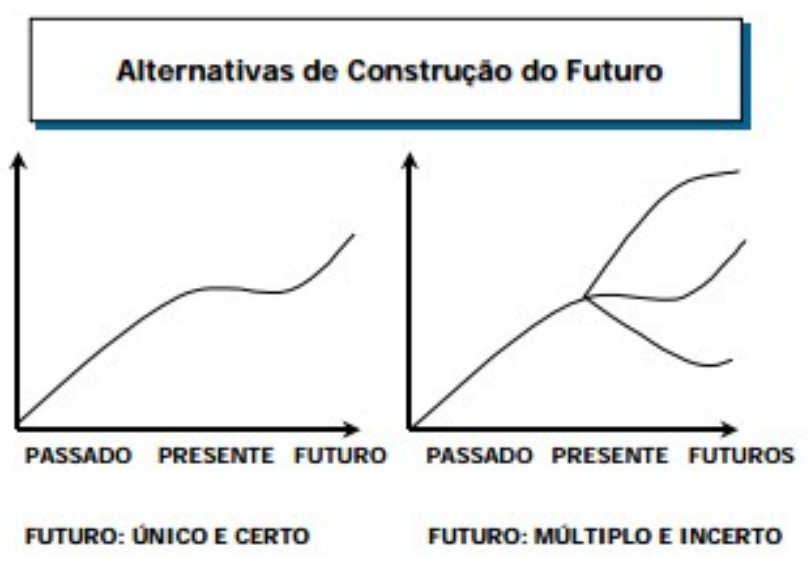

Figura 2: Modelos de Estudo do Futuro Fonte: Cardoso et al (2005 apud CASTRO; LIMA, 2001) 
Há uma grande variedade de métodos e técnicas utilizadas para a prospecção do futuro, categorizadas por Kotler (1996) como:

a) Extrapolação de tendências - ajuste de curvas mais confiáveis a séries de tempos passados;

b) Correlação de tendências - indicadores de avanço e retrocesso a partir de séries de tempos;

c) Modelagem econométrica - equações para descrever o sistema vigente;

d) Análise de impacto cruzado - conjunto de tendências-chave e impacto de uma delas sobre as demais;

e) Previsão de demanda/risco - convergência e apelo entre eventos-chave e tendências importantes da sociedade;

f) Método Delphi - Rodadas com especialistas que estabelecem as variáveis e indicadores críticos e avaliam os eventos prováveis, havendo o aperfeiçoamento das hipóteses e julgamentos após cada fase (busca do cenário mais provável);

g) Cenários múltiplos - construção de imagens de futuros alternativos, cada um com consistência interna e tendo relevância, além de certa probabilidade de ocorrência.

O método Extrapolação de Tendência se aplica por meio de estudos matemáticos com base nas tendências passadas e históricas. Geralmente é utilizado em áreas de maiores estabilidades, ou seja, em áreas que possuem poucas influências externas e internas. Esse tipo de prospecção é utilizada em curtos períodos de tempo, tendo em vista que os fatores que agiram no passado e que continuam agindo no presente também irão agir no futuro. Assim, quanto menor o prazo, menores são as alterações que ocorrem e maior probabilidade de acerto.

O método Correlação de Tendência busca uma análise entre diferentes fatores que se correlacionam para a construção de dados futuros. Trata-se de um método quantitativo com emprego de dados estatísticos. $O$ método de Modelagem Econométrica utiliza-se de cálculos estatísticos, sendo usualmente aplicado em estudos econômicos para um longo prazo. Pode ser aplicado como auxílio de análise avaliativa de concessão de crédito para empresas, entre outras utilizações. Já o método de Impacto Cruzado corresponde a um método qualitativo que busca em subambientes destacar os principais fatores de ação e reação do futuro, ou seja, analisam-se os fatores que se interrelacionam e que possam gerar subsistemas 
secundários. É utilizado principalmente em estudos ligados a tecnologias. O método de caráter quantitativo, Previsão de Demanda/Risco é utilizado principalmente por empresas que trabalham com estoques para minimizar perda e maximizar os lucros. $O$ método pode ser utilizado para um curto, médio ou longo prazo.

Diante de diferentes métodos para a prospecção de futuro e averiguando aquele que melhor atendesse as necessidades para a resolução dos objetivos propostos, optamos pela utilização do método Delphi, em combinação com o método de Cenários Múltiplos.

A palavra Delphi tem sua origem inspirada na cidade grega Delfos, local do santuário religioso oráculo de Delfos. Consagrado ao deus Apolo, divindade da profecia, o oráculo tinha como principal função a de ser fonte de conhecimento e de prever o futuro. (SILVA, 2014). As respostas do oráculo eram reveladas pelas pitonisas, que, em transe, revelavam o futuro. As profecias eram utilizadas como forma de orientação nas decisões importantes, sendo elas relacionadas a aliados de guerra, à saúde, entre outros. Dessa forma, acreditava-se que era possível evitar um futuro indesejado.

Associado à função do oráculo, o método Delphi, ou técnica de Delfos ${ }^{5}$, foi desenvolvido como um método prospectivo. O método possui como objetivo "aclarar o futuro e melhorar prognósticos e cálculos sobre o que pode acontecer nesse mesmo futuro". (RAMOS, 2005). Desenvolvido por um grupo de pesquisadores da empresa Rand Corporation - instituição sem fins lucrativos para desenvolvimento de pesquisas e soluções para as políticas públicas dos EUA - em Santa Mônica, Califórnia, como técnica de investigação, foi por Dalkey (1969) caracterizado como método formado por um conjunto de procedimentos para a convergência de opiniões. A técnica de Delphi foi aprimorada por Olav Helmer - matemático e filósofo - ao utilizar de opiniões de "experts" como forma de prospectar o futuro.

O método Delphi pode ser utilizado de forma satisfatória para que as previsões sejam alcançadas a partir da opinião de peritos. (LEVINE, 1984) A utilização de opiniões de "experts", "peritos" ou "especialistas" surge a partir do ditado popular "duas cabeças pensam melhor do que uma" (JAIMES, 2009). Para a Equipe da Dimensão Institucional do Instituto de Estudos Avançados (2004), os fundamentos do Delphi se baseiam:

5 A bibliografia e teóricos levantados referem-se ao Delphi como método ou técnica, porém não há diferença em sua aplicação, apenas escolha terminológica. 
No uso estruturado do conhecimento, da experiência, e da criatividade de um painel de especialistas, no pressuposto de que o julgamento coletivo, quando organizado adequadamente, é melhor do que a opinião de um só indivíduo, ou mesmo de alguns indivíduos desprovidos de uma ampla variedade de conhecimentos especializados. (INSTITUTO DE ESTUDOS AVANÇADOS, 2004, p. 5-6).

O método Delphi tem se mostrado útil em diversas áreas, empresariais ou não. Possui como base a convergência de opiniões; não se limita apenas a identificar riscos, sendo comumente utilizado para construções de cenários.

O termo da técnica de cenário foi extraído das artes, precisamente do teatro e do cinema (GRISI; BRITTO, 2003, p.05) e referem-se a cenário como "um conjunto de técnicas investigativas que visam a identificar os vários futuros possíveis e os caminhos que nos conduzirão até alguns deles".

Diante das diferentes contribuições, a técnica de cenários é uma combinação para além da matemática, sendo influenciada também por questões culturais. Além disso, a técnica permite um olhar crítico e por vezes não imaginado do futuro, para que em posse dos cenários os pontos fortes e fracos de cada um possam ser trabalhados. No trabalho de Schwartz (2006), a construção de cenários não se refere a previsões por considerar ser impossível prever o futuro com elevado grau de certeza:

[...] em vez disso, os cenários são veículos que ajudam pessoas a aprender. Ao contrário da previsão tradicional de negócios ou da pesquisa de mercado, os cenários apresentam imagens alternativas de futuro; eles não extrapolam simplesmente as tendências presentes. (SCHWARTZ, 2006, p. 17).

O método de Cenários Múltiplos fortalece uma visão estratégica sobre diferentes ocorrências futuras sendo estas favoráveis ou não. Este método possui, na literatura, inúmeras formas de ser aplicado com a utilização de diferentes técnicas. 0 que são cenários?

\begin{tabular}{llll}
\hline \multicolumn{1}{c}{ São Cenários } & & \multicolumn{1}{c}{ Não São Cenários } \\
\hline - & $\begin{array}{l}\text { Descrições de futuros alternativos } \\
\text { plausíveis }\end{array}$ & - & Previsões \\
\hline - & $\begin{array}{l}\text { Diferentes visões de futuro } \\
\text { significantes e estruturadas }\end{array}$ & $\bullet$ & $\begin{array}{l}\text { Variações em torno de uma } \\
\text { situação de base }\end{array}$ \\
\hline - & $\begin{array}{l}\text { Movimentos da dinâmica que } \\
\text { envolve o futuro }\end{array}$ & $\bullet$ & $\begin{array}{l}\text { "Tiros certeiros" ou "pontos } \\
\text { finais" }\end{array}$ \\
\hline - $\begin{array}{l}\text { Visões do futuro focadas para } \\
\text { tomadas de decisão }\end{array}$ & $\bullet$ & $\begin{array}{l}\text { Visões generalizadas de futuros } \\
\text { desejados }\end{array}$ \\
\hline - $\begin{array}{l}\text { Resultado de "insights" e } \\
\text { percepções de especialistas }\end{array}$ & $\bullet$ & Produtos de "futuristas" externos \\
\hline
\end{tabular}

Figura 3 - O que são cenários?

Fonte: Adaptado de Fischer (2007 apud RALSTON; WILSON, 2006) 
Diante das diferenciações, é possível observar que a técnica de Cenários corrobora com a visão dos estudos prospectivos, segundo a qual não há pretensão de encontrar um futuro determinado, mas de esboçar diferentes probabilidades de futuro, considerado como "simulações" de prováveis futuros (BROCHETTO, 2007).

Tendo em vista a proposta aqui apresentada, seguem as análises das entrevistas. A partir da análise das respostas, foi possível constatar 03 tipos de fatores de influência para o futuro do prédio da antiga fábrica Santa Amélia, que estão interligados, em uma cadeia de ação e reação, categorizados como:

a) Fator inicial. $O$ fator inicial é aquele que se encontra como base para iniciar a cadeia de eventos futuros. São considerados aqui as políticas públicas e o planejamento.

b) Fatores intermediários. Os fatores intermediários são aqueles que se posicionam entre os iniciais e os finais (TSUJI,2002, p.49). São considerados aqui a segurança, acessibilidade, infraestrutura, gestão, recursos financeiros e logística.

c) Fatores finais: Os fatores finais são as consequências das ações iniciais e intermediárias, que irão construir o futuro. São considerados aqui ensino, turismo e comunidade.

Sabendo-se que o futuro é incerto e múltiplo, foram construídos 03 cenários distintos, sendo um possível, um otimista em relação ao possível e um pessimista. No desenvolver da pesquisa tem-se a primeira, segunda e terceira rodada Delphi.

Primeira rodada Delphi: A primeira etapa foi realizada por meio de entrevistas com 11 participantes de diferentes áreas denominada de "área acadêmica", "agentes locais e públicos" e "agentes ligados ao patrimônio". Com 100\% das entrevistas, definiu-se por meio da análise do conteúdo 11 (onze) fatores de futuro que irão fazer parte da construção dos cenários, sendo eles: os fatores inicias (poder público e planejamento), os fatores intermediários (segurança, logística, acessibilidade, infraestrutura, gestão e recursos financeiros) e os fatores finais (turismo, comunidade e ensino). Após a identificação dos fatores foi possível uma análise geral da atual situação do entorno e da fábrica a partir da opinião dos especialistas, o que resultou na forma como os fatores identificados passarão a interagir entre si. No entanto, apenas uma única etapa não permitiu a construção dos cenários, pois houve pequenas divergências entre as opiniões, sendo necessário um consenso entre os participantes para validar-se o Delphi.

Na segunda rodada Delphi foi possível ter um resultado por meio da aplicação de um questionário Delphi. Para essa etapa, foram obtidas apenas $72,2 \%$ de taxa de 
retorno, após a extensão do prazo de 1 semana para quase 3 meses, por não se ter alcançado no primeiro momento um percentual de retorno satisfatório. O resultado do questionário foi analisado de forma qualitativa, resultando um consenso de opinião.

Os dados encontrados indicaram as tendências dos três cenários futuros, denominados de "O prédio da fábrica Santa Amélia revitalizando o Centro de São Luís como espaço de ensino" sendo esse o cenário possível; "O Complexo da fábrica Santa Amélia como destaque de ensino e visitação" sendo o cenário otimista e "O prédio da fábrica Santa Amélia restaurada para degradação" sendo o cenário pessimista. As descrições dos cenários posicionam o prédio da Santa Amélia como um espaço de ensino, concretizando o planejamento do seu projeto inicial, independentemente dos cenários.

No cenário possível, o patrimônio ganha força como espaço de ensino, em formar turismólogos e hoteleiros para o mercado de trabalho, além de desenvolver os cursos de Turismo e Hotelaria, com destaque para os trabalhos de pesquisa e extensão, mesmo em meio ao contingenciamento de recursos vivenciado pela UFMA. Dessa forma, a atividade turística não é vista como prioridade; aparece de forma sutil com a visitação ao patrimônio e ao museu da indústria, proporcionada pelos próprios discentes. Nesse cenário, as políticas públicas, em parceria com a gestão da UFMA, tornam-se atores responsáveis pela melhoria/revitalização da região e consequentemente dos benefícios para a comunidade e para o alunado. Ainda assim, há dificuldades de acessibilidade (ruas, alagamento no período de chuvas intensas, tráfego) não especificamente do patrimônio da fábrica, mas do entorno que a compõe, sendo um fator encontrado em todos os cenários, logo, um fator de risco que precisa ser olhado com maior atenção pelos atores sociais.

No cenário otimista, o complexo da fábrica Santa Amélia aparece vivenciando um contexto turístico em São Luís, como espaço cultural, de lazer e eventos, tornando-se um atrativo turístico, fazendo parte também da criação de um roteiro com o Mercado Central (construído em 1864), o prédio que abrigou o Sioge (Serviço de Imprensa e Obras Gráficas do Estado do Maranhão) ${ }^{6}$ e a Fonte das Pedras ${ }^{7}$, sem

6 O prédio, construído no final do século XIX, abrigou a extinta Fábrica Progresso, depois foi sede do Serviço de Imprensa e Obras Gráficas do Estado (SIOGE). Após reforma, que está em andamento, o prédio irá custodiar os achados arqueológicos da área de implantação da Refinaria Premium, em Bacabeira-MA, e os artefatos que fazem parte do projeto acadêmico desenvolvido pelo Laboratório de Arqueologia da Universidade Federal do Maranhão. O prédio abrigará o curso de História e a PósGraduação em Arqueologia da UFMA.

7Construída pelos holandeses, no século XVII, a Fonte das Pedras possui referência a dois fatos históricos maranhenses: a expulsão dos franceses, em 31 de outubro de 1615, pelo comandante 
deixar a sua principal atividade, o espaço de ensino. Neste cenário, o Hotel Escola também ganha destaque, como participante do complexo, oferecendo ao turista e visitante uma experiência singular em um casarão antigo no centro de uma cidade histórica.

O cenário pessimista retrata o descaso pelos atores sociais, agravado pela falta de recursos financeiros, tendo o prédio da fábrica Santa Amélia uma nova vivência de tempos áureos como espaço de ensino que logo se esgotará pela falta de políticas públicas, pela dificuldade de acesso e por falta de preservação do seu patrimônio.

É relevante mencionar que parte da descrição desse cenário futuro tem grande semelhança com o cenário atual em relação à segurança, à infraestrutura, à acessibilidade e ao turismo. A região não tem grandes perspectivas de melhorias, nem no tocante ao patrimônio tombado.

Tendo-se descrito os cenários, a terceira etapa, terceira rodada Delphi, foi finalizada por meio de uma mesa redonda com a presença de participantes da pesquisa e de um membro externo. A mesa redonda serviu como um momento de reflexão dos cenários apresentados, sensibilizando os atores sociais para os pontos fortes e fracos, além de validar a pesquisa e os cenários como possíveis de acontecer. Têm destaque, nessa etapa, os receios enfrentados pela mudança do curso para a fábrica, sendo a representação do meio acadêmico, hoje, mais propensa ao cenário pessimista, apesar de se manterem ainda na esperança de concretização do cenário otimista. Outro fator relevante encontrado nessa etapa refere-se à parceria entre os setores público e privado como fundamental para o desenvolvimento do turismo na região e para a sustentabilidade do próprio complexo. Na construção dos cenários, altera-se o fator recursos financeiros, antes fator intermediário para fator que inicia uma mudança, e que reverbera nos fatores intermediários (ação e reação).

A pesquisa, que a princípio buscou relacionar o patrimônio em um contexto turístico, ganhou maior abrangência de contato com outras áreas do conhecimento ao longo das etapas, como as políticas públicas, o planejamento e a economia. Essa interdisciplinaridade demonstra a necessidade de se trabalhar de forma sistêmica, para além do objeto estudado.

português Jerônimo de Albuquerque, que acampou no local com sua tropa antes da expulsão, e a invasão holandesa, em 1641, ocasião em que suas águas foram canalizadas pelos batavos. 


\section{Considerações Finais}

O Brasil, apesar de inserido tardiamente no processo de industrialização, também percorreu e sofreu os mesmos percalços de outros países pioneiros da Revolução Industrial, sobre a questão do desaparecimento e obsoletização dos antigos prédios e parques fabris. A transição entre o abandono e o reconhecimento da importância histórica do patrimônio foi responsável pela emergência de conceito de patrimônio industrial e da disciplina arqueologia industrial.

A partir do reconhecimento do estudo dos processos sociais, culturais e materiais da indústria, a sociedade passa a preocupar-se em preservar o patrimônio fabril por meio do tombamento e reuso do patrimônio. Devido as suas peculiaridades arquitetônicas encontraram-se para essas edificações uma nova utilização, ligada principalmente a fins culturais, como museus e espaços de lazer. Nesta questão insere-se a atividade turística como forma de conservação e preservação por meio da difusão do patrimônio industrial, deixando-se seu caráter de "elefante branco" para a administração, para se tornar um atrativo cultural, que ganha espaço no mercado a partir do segmento do turismo cultural. Além de sua reconversão em espaços culturais, identifica-se com sucesso, o reuso desses patrimônios transformados em espaços de ensino, a exemplo da antiga fábrica Santa Amélia.

Sabendo-se dos projetos grandiosos da UFMA, destinado ao prédio da antiga fábrica Santa Amélia, de transformá-la em um complexo de ensino dos cursos de Turismo e Hotelaria, surgiu a motivação desta pesquisa em descrever cenários futuros para esse patrimônio, cuja expectativa vai além da fábrica como espaço de ensino, pois sua recuperação pode estimular o desenvolvimento turístico da região em que se localiza. O período de tempo escolhido para estas projeções foi de 10 anos (2017 2027), realizado por meio do método Delphi.

Diante do que foi estudado, avalia-se que, entre os cenários, o turismo ganha força principalmente em relação à consolidação do complexo como espaço cultural, pois, com a sua reutilização e o aparato da segurança e infraestrutura (considerando o cenário possível e otimista), é possível tornar mais acessível o desenvolvimento de projetos para a região, que considerem a cultura, a história e a importância do prédio, utilizando as edificações do complexo como verdadeiros equipamentos turísticos propagados dentro e fora de São Luís. Nesse sentido, o investimento de recursos para a consolidação da segurança, da infraestrutura e das políticas públicas e culturais 
fortalece o interesse dos poderes público e privado, para que compartilhem do mesmo interesse de desenvolver a região através de um turismo sustentável.

\section{Referências Bibliográficas}

Biblioteca Digital Câmara dos Deputados. COLEÇÃO DAS LEIS DO IMPÉRIO DO BRASIL, 1841-1850. Disponível em: <http://www2.camara.leg.br/atividadelegislativa/legislacao/publicacoes/doimperio> Acesso em: 12 jul. 2016.

BROCHETTO, Luiz Henrique (2007). Análise de cenários lógicos intuitivos como apoio ao planejamento estratégico: pesquisa-ação em uma pequena empresa de educação a distância (Dissertação de Mestrado). Itajubá. Universidade Federal de Itajubá Disponível em: <http://adm-net-a.unifei.edu.br/phl/pdf/0032503.pdf>Acesso em: 10 jul. 2016.

CARDOSO, Luiz Reynaldo de Azevedo; ABIKO, Alex Kenya; HAGA, Heitor Cesar Rioge; INOUYE, Kelly Paiva. Prospecção de futuro e Método Delphi: uma aplicação para a cadeia produtiva da construção habitacional. Ambiente Construído, Porto Alegre, v. 5, n. 3, p. 63-78, jul./set. 2005.

CARVALHO, Conceição Belfort. A genealogia do patrimônio em São Luís: da Athenas à capital da diversidade. 2009. Tese (Doutorado) - Faculdade de Ciências e Letras, Universidade Estadual Paulista Júlio de Mesquita Filho, 2009. Disponível em: $<$ https://repositorio.unesp.br/bitstream/handle/11449/103556/carvalho_cmb_dr_arafcl.p df?sequence=1\&isAllowed=y> Acesso em: 12 jul. 2018.

CASTRO, A. M. G.; LIMA, S. M. V. Curso de capacitação de equipes para estudos prospectivos de cadeias produtivas industriais. MDIC/STI, 2001.

CESQUIM, TIAGO LUIS. CONSTRUÇÃO DE CENÁRIOS PROSPECTIVOS História, conceitos e métodos. Monografia apresentada ao Programa San Tiago Dantas de PósGraduação em Relações Internacionais da UNESP,2009. Disponível em: $<$ https://tiagocesquim.files.wordpress.com/2012/05/cesquim-tiago_construc3a7c3a3ode-cenc3a1rios-prospectivos.pdf> Acesso em: 07 mar. 2016.

DALKEY, N. C. The Delphi Method: an experimental study of Group Opinion. Rand Corporation. Santa Mônica - California, p. 87. 1969.

EQUIPE DA DIMENSÃO INSTITUCIONAL DO INSTITUTO DE ESTUDOS AVANÇADOS - IEA. Projeções relativas à dinâmica da dimensão global e visualização prospectiva para 2007, 2015 e 2022. IEA, São Paulo, 2004. Disponível em:

<http://www.iea.usp.br/iea/observatorios/futuro/projeto/prospectivainstitucional.pdf> Acesso em: 08 mar. 2017.

GRISI, C. C. H.; BRITTO, R. P. Técnica de Cenários e o Método Delphi: uma aplicação para o ambiente brasileiro. In: SEMEAD - SEMINÁRIOS EM ADMINISTRAÇÃO FEA-USP, 6., 2003, São Paulo. Anais. Disponível em: <http://www.ead.fea.usp.br/Semead/6semead/MKT.htm>. Acesso em: 6 jan. 2017. 
Instituto do Patrimônio Histórico e Artístico Nacional (IPHAN). Processo de Tombamento nº 1144-T-85, Fábrica Santa Amélia, São Luís, Maranhão.

JAIMES, M. C. El método Delphi: cuando dos cabezas piensan más que una en el desarrollo de guías de práctica clínica. Revista Colombiana de Psiquiatría, Bogotá, v. 38, n. 1, Jan./Mar. 2009.

KOTLER, P. Administração de marketing. São Paulo: Editora Atlas S.A, 1996.

KÜHL, Beatriz Mugayar. História e Ética na Conservação e na Restauração de Monumentos Históricos. CPC, São Paulo, v.1, n.1, p. 16-40, nov. 2005/abr. 2006.

Algumas questões relativas ao patrimônio industrial e à sua preservação. Revista eletrônica do Iphan, São Paulo, 2006.

LEVINE, A. A model for health projections using knowledgeable informants. Wld. Health Stat. Quart., 37, 1984.

LIMA, Ludmilla Sandim Tidei de. Diretrizes para intervenções em edificações ferroviárias de interesse histórico no Estado de São Paulo: as estações da Estrada de Ferro Noroeste do Brasil. 2006. Dissertação (Mestrado) FAUUSP, São Paulo, 2006.

LOPES, J. A. V. Capital moderna e cidade colonial: o pensamento preservacionista na história do urbanismo ludovicense. 2004. Dissertação (Mestrado em Desenvolvimento Urbano) - Programa de Pós-Graduação em Desenvolvimento Urbano, Universidade Federal de Pernambuco, Recife, 2004.

MARCIAL, E. C.; GRUMBACH, R. S. Cenários Prospectivos:como construir um futuro melhor. $3^{\mathrm{a}}$ ed. Rio de Janeiro: FGV, 2005.

MARCIAL, E. C. Aplicação de metodologia de cenários no Banco do Brasil no contexto da inteligência competitiva. Dissertação (Mestrado).L'Université de Droite et des Sciences d'Aix - Marseille - Faculté des Sciences et Techniques de Saint Jérome - Centre de Recherches Rétrospectives de Marseille - CRRM 13397 - Marseille - Cedex 20 - France: 1999.

MEIRELES, Mário M. História do Maranhão. 4. ed. Imperatriz: Ética, 2008.

RALSTON, B.; WILSON, I. The Scenario Planning Handbook: Developing Strategies in Uncertain Times, Thomson/South-Western, 2006.

RAMOS, A. R. C. D. C. V. O Termalismo em Portugal:dos factores de obstrução à revitalização pela dimensão turística. Tese de Doutorado. Universidade de Aveiro, Aveiro, p. 683, 2005.

SILVA, M. A. D. O. Usos dos oráculos délficos em Plutarco. Nóesis.Revista de Ciencias Sociales y Humanidades, Juárez, v. 23, n. 45, p. 206-220, enero-junio 2014.

SCHWARTZ, Peter. A arte da visão de longo prazo: planejando o futuro em um mundo de incertezas. 4. ed. Tradução Luiz Fernando M. Esteves. Rio de Janeiro: BestSeller, 2006. 216 p 
TSUJI, Tetsuo. Região dos Lençóis Maranhenses: cenários futuros de ecoturismo e desenvolvimento sustentável. Curitiba: Juruá,2002. 172p. 